\title{
Optimizing a Beverage Can Production Line by MATERIAL FLOW SiMUlation
}

\author{
Popa Cicerone Laurentiu, Cotet Costel Emil, Constantin Florin, Zaleschi (Negrea) \\ Violeta - Carmen
}

University Politehnica of Bucharest, Machines and Manufacturing Systems Department, No.313, Spl. Independentei, sector 6, Bucharest, 060042, Romania

\begin{abstract}
The paper proposes an optimizing algorithm based on a virtual model of a processing architecture. To illustrate this algorithm we have chosen a beverage production line, a diffused processing architecture using productivity as the main performance indicator. The material flow management of this beverage can production line will be based on its virtual model in order to identify and eliminate material flow concentrators and increase productivity. Simulation will be used to diagnose the initial performance of the system structural elements as well as to validate the optimized system performances after eliminating the bottlenecks. The algorithm could easily be adapted to any manufacturing or processing architecture based on discrete material flow, where the circulating entities (e.g. parts) are distinct and countable.
\end{abstract}

Keywords: beverage can; production line; simulation; virtual model; material flow management
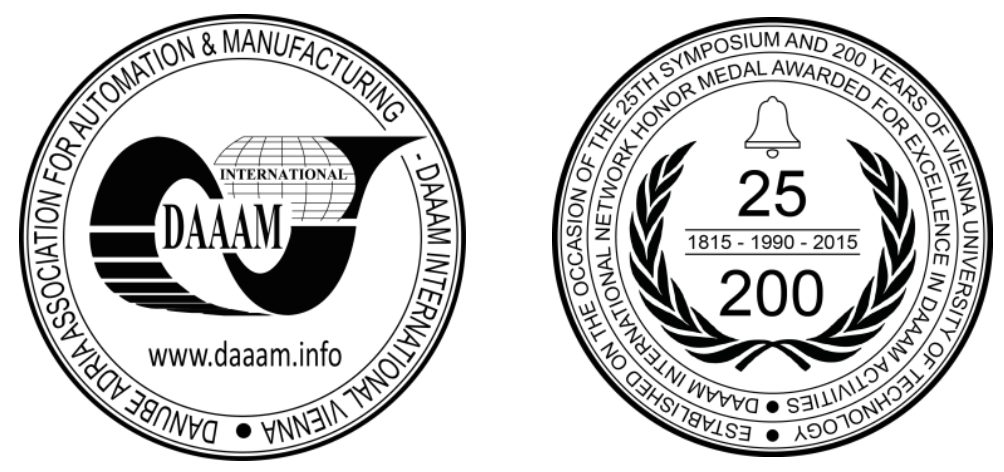

This Publication has to be referred as: Popa, C[icerone] L[aurentiu]; Cotet, C[ostel] E[mil]; Constantin, F[lorin] \& Zaleschi Negrea, V[ioleta] -[ Carmen] (2016). Optimizing a Beverage Can Production Line by Material Flow Simulation, Proceedings of the 26th DAAAM International Symposium, pp.0206-0211, B. Katalinic (Ed.), Published by DAAAM International, ISBN 978-3-902734-07-5, ISSN 1726-9679, Vienna, Austria DOI: $10.2507 / 26$ th.daaam.proceedings.028 


\section{Introduction}

The modern manufacturing constraints should produce highly customizable and innovative products; continuously increase their quality and decrease the time-to-market and costs in order to gain competitive advantages. All these determined a focus on optimizing the manufacturing and processing systems starting early from their design phase by using MFT (Material Flow Theory) and specific simulation software tools [1]. Depending on product characteristics and production type, several classical architectures of manufacturing and processing systems (assembly line, flexible manufacturing system, flexible manufacturing cell, job shop, etc.) can be deployed in a factory [2]. These architectures can be analyzed in conjunction with MFT applications and specific algorithms in the MFM (Material Flow Management) area, and optimized based on mathematical and virtual modelling. To optimize a material flow, one should focus on maximizing or minimizing specific parameters according with their nature (for instance, cost is a minimizing parameter, while productivity is a maximizing parameter) [3]. We present in this paper an optimization algorithm based on identifying the points where the material flow is slowed down or even blocked (flow concentrators or bottlenecks) and finding solutions to eliminate such problems with or without modifying generic architecture [4].

In a work post, one or several operations/activities can take place using processes and machines. In an attempt to decrease the overall production time, there are approaches which consider eliminating the transport \& transfer times between work posts by combining in a single machine, two (or more) manufacturing processes. As known, the manufacturing processes can be classified as: subtractive - involving material removal (such as milling, drilling, turning/lathing, etc.), additive - involving material addition layer-by-layer (stereolithography, fused deposition modelling, selective laser sintering, etc.) and with material distribution (injection molding, forming, casting, etc.) [5].

In the hybrid manufacturing work post, additive and subtractive processes can be combined within a single machine, completely computer-controlled, in order to benefit of the advantages of each technology, such as complex geometry, controlled geometry, functional graded material parts - for additive fabrication, and high precision and surface quality or very good mechanical properties - for subtractive fabrication [6][7]. The presented algorithm covers all these situations, producing a virtual manufacturing model used to configure an optimized manufacturing architecture for different purchase orders of the customers [8]. The algorithm could also be extended for virtual enterprises and collaborative networks, using basically the same software solution [9].

We will illustrate this algorithm using a simple application from beverage industry. Beverage cans were produced for the first time in the US in 1935. Since then there have been many innovations in the beverage cans production line and as a result the beverage cans became more light (about $5 \%$ of the total weight when full). Today, a beverage can weighs $40 \%$ less than its equivalent from the 70 's. An empty beverage can weighs about 13.5 grams and has a thickness equal to the thickness of a human hair.

The beverage cans capacity varies from country to country: $150 \mathrm{ml}, 200 \mathrm{ml}, 222 \mathrm{ml}, 237 \mathrm{ml}, 250 \mathrm{ml}, 330 \mathrm{ml}$, $341 \mathrm{ml}, 350 \mathrm{ml}, 355 \mathrm{ml}, 375 \mathrm{ml}, 440 \mathrm{ml}, 473 \mathrm{ml}, 500 \mathrm{ml}, 550 \mathrm{ml}, 568 \mathrm{ml}$ and $1000 \mathrm{ml}$.

The beverage cans are $100 \%$ recyclable, which means that are economically efficient and environmentally friendly and can be recycled indefinitely.

The advantages of using beverage cans are:

- cost efficient,

- high transport efficiency,

- $360^{\circ}$ brand exposure,

- variety of sizes to match application/market conditions,

- content is protected from light and air,

- $\quad$ long shelf life,

- $\quad$ easy to recycle. [10]

The beverage can contains two main parts:

a) the can body (the neck, the can wall and the can base)

b) the lid (EOE - Easy Opening End)

The beverage can is used for packaging of: water, juices, beer, tea, soft drinks etc. There are many can producers all over the world (including Romania): Rexam Beverage Cans Americas, Crown Holdings Inc., Ball Corporation, Can-Pack Group etc. The production line from our case study is placed in Romania. 


\section{The beverage cans production line modeling using Witness 14}

The production line from our case study is placed in Romania. The goal of the simulation is to realize a diagnosis and to propose an optimized solution including an increase in terms of productivity by eliminating the material flow concentrators. We have used Witness 14 for the modeling of the production Line (see Fig. 1). The beverage cans production line has the following structural elements:

- The cupping press - the machine that makes the beverage can.

- The bodymaker - the machine that makes the body of the beverage can.

- The washer - the machine that washes the beverage cans.

- The decorator - the machine that prints (on) the cans.

- The oven that dries the cans after they were printed.

- $\quad$ ISM - the machine that applies the interior protection polymer layer.

- $\mathrm{IBO}$ - the oven that dries the interior of the can.

- The necker. The machine that narrows and borders the beverage cans.

- Work point for packaging the cans.

- The conveyors - they cover the internal transport of the cans from one machine to another.

- The buffer - spare lanes that insure the continuous functioning of the line in case of breakdown. There are 4 of them, one for each area that can cause blockages.

- Production operators - they insure the good functioning of the machines. There are 15 operators: one at the press, 4 at the bodymaker, 1 at the washer, 4 at the printer, 2 at the ISM and necker and 3 at the work point for packaging.

- The CTC (metc). It insures the final control of the beverage cans.

- Human resources coordinator

We have modelled the system's structural elements using the database available in the Witness 14 simulation software. For the virtual model, the links between the system's structural elements were created using the system real parameters in order to reproduce the material flow trajectories.

\section{The beverage cans production line modeling using Witness 14}

In the figure 2 we see the simulation of the production line of aluminum cans where the press is supplied with rolls of aluminum sheets - aluminum coil from the warehouse. It produces 12 workpiece cans with every beat of its mould and the leftover material is recycled. The workpiece cans are transferred with the help of a transfer conveyer to the conveyer that distributes the workpiece cans to the 9 bodymakers (bm1, bm2...bm9) in order to manufacture the beverage can. After the making of the cans they are transported by a conveyor to the washer that washes away the oils used in manufacturing the cans.

A conveyor transfers the washed and dried cans to the two printers where they are printed. The cans that have been printed are dried on ovens and are collected by the feeding conveyer of the machine that makes the inside protective layer of the cans. Afterwards they are transferred to the place where the interior protection coverage will be performed.

After the interior protective layer is done and the cans are dried in the oven they arrive at the narrowing machine where the neck of the can is narrowed and the necker is made. The narrowing of the upperside of the can is done according to the final parameters in order to prepare the can for the attaching of the cover. The conveyer transfers the can narrowed at the top to the palletizing area where the cans are gathered in pallets of 5000 pieces in a buffer area and then the packaging and tying takes place. After packaging the pallets are transferred to a storage place for being transferred to the client.

Using this virtual model, a simulation was performed in order to identify the bottlenecks and the long waiting times of the system. In the preliminary simulation, the parameters for the system's components were set to their default value. During the preliminary simulation the structural elements were parameterized in conformity with the existing settings from the production line equipment. A diagnosis and a confirmation of productivity were desired. Following the preliminary simulation, reports have been generated for all the structural elements of the system. 


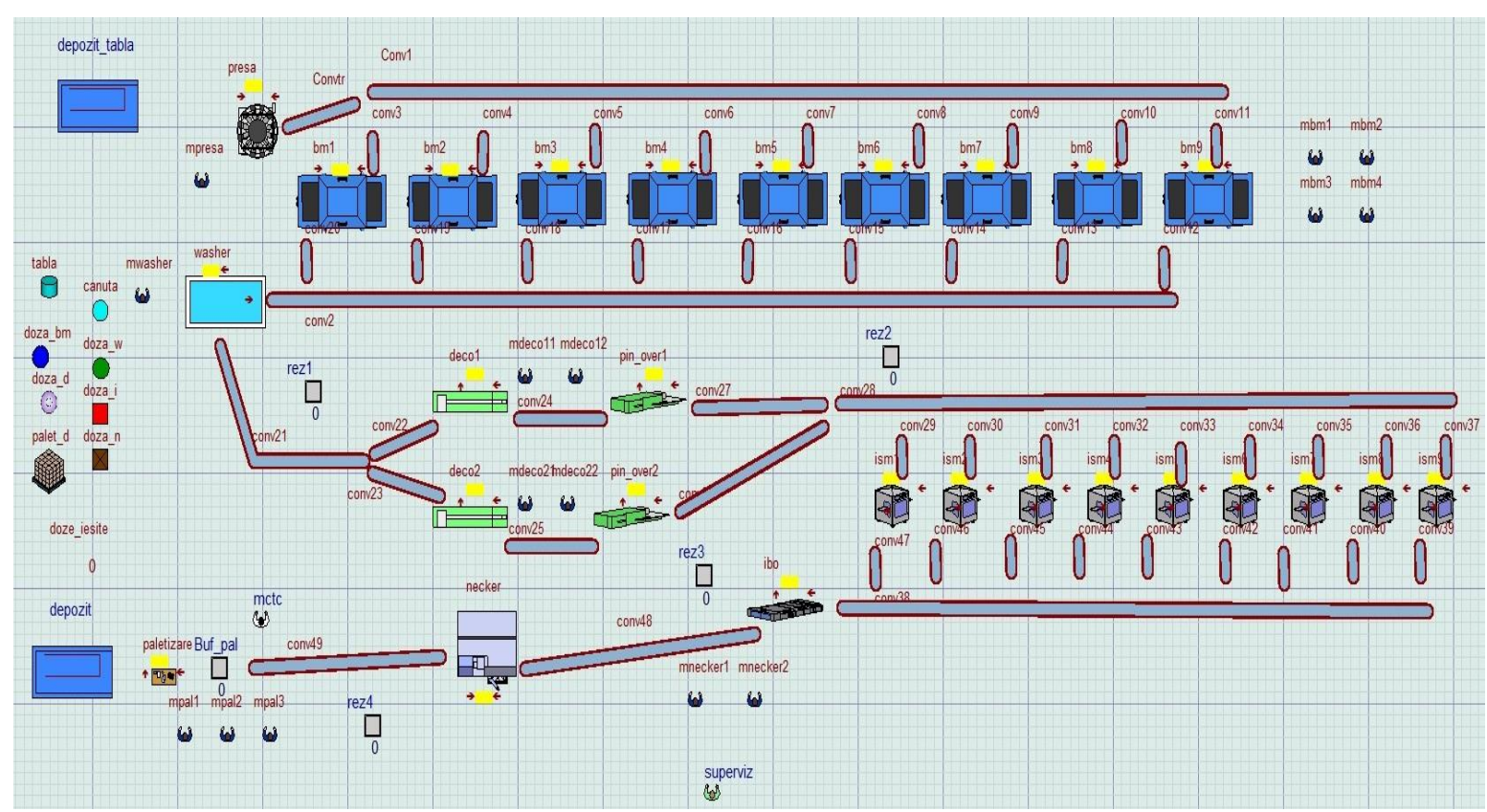

Fig. 1. The preliminary system architecture in Witness 14

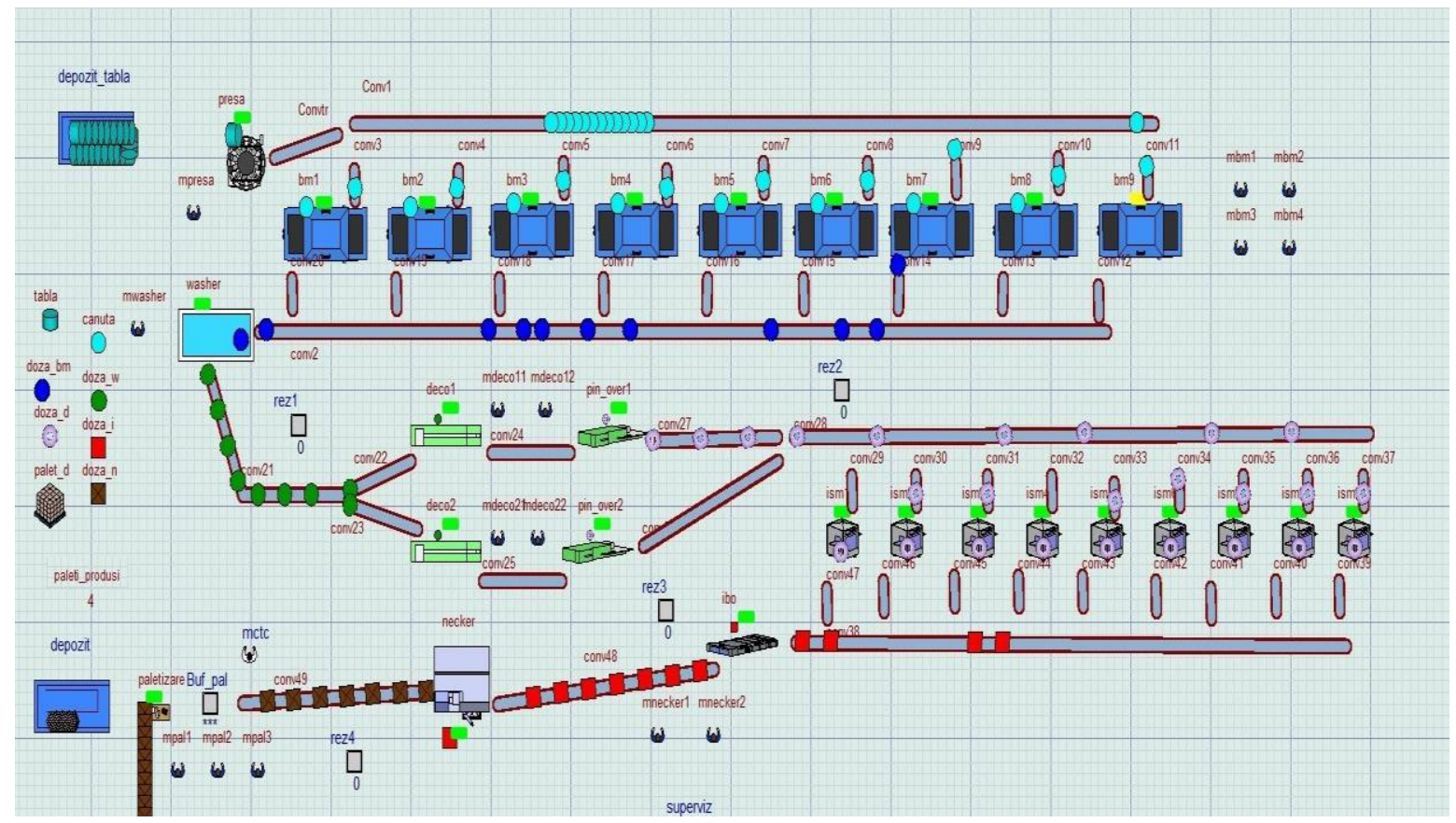

Fig. 2. The beverage cans production line during the simulation

Following the simulation of the preliminary architecture, the information received from the producer is confirmed after 12 hours 1.800 .000 beverage cans are obtained. According to the generated reports, problems were identified at:

- the cupping press - blockage up to $20 \%$;

- the washer - where the waiting time is of $10 \%$;

- the necker - where the waiting time is of $10 \%$;

- small blockages at some of the bodymakers (between 4 and 10\%)

- small blockages at the ISM where there are blockages between $3 \%$ and $9 \%$.

After the identification and confirmation of the flow concentrators and of the areas that slowed down the flow, a functional remodeling of the system was done. A technological remodeling would not have been possible due to the requirements of the producer. Through the functional remodeling the functioning parameters for some structural elements were modified. In this process, the technical characteristics from the handbook of every equipment from the production line were taken into account. The parameters will be modified in successive simulations until an optimized 
version of the system in terms of productivity will be obtained. We have performed several simulations with different parameter's versions, we compared the reports and we retained the best version which had the biggest increase of productivity compared to the original version of the system, taking into account the avoidance of bottlenecks and long waiting times. Following the simulation, the graphics presented below were obtained, which reveal an improvement in the functioning of the production line.
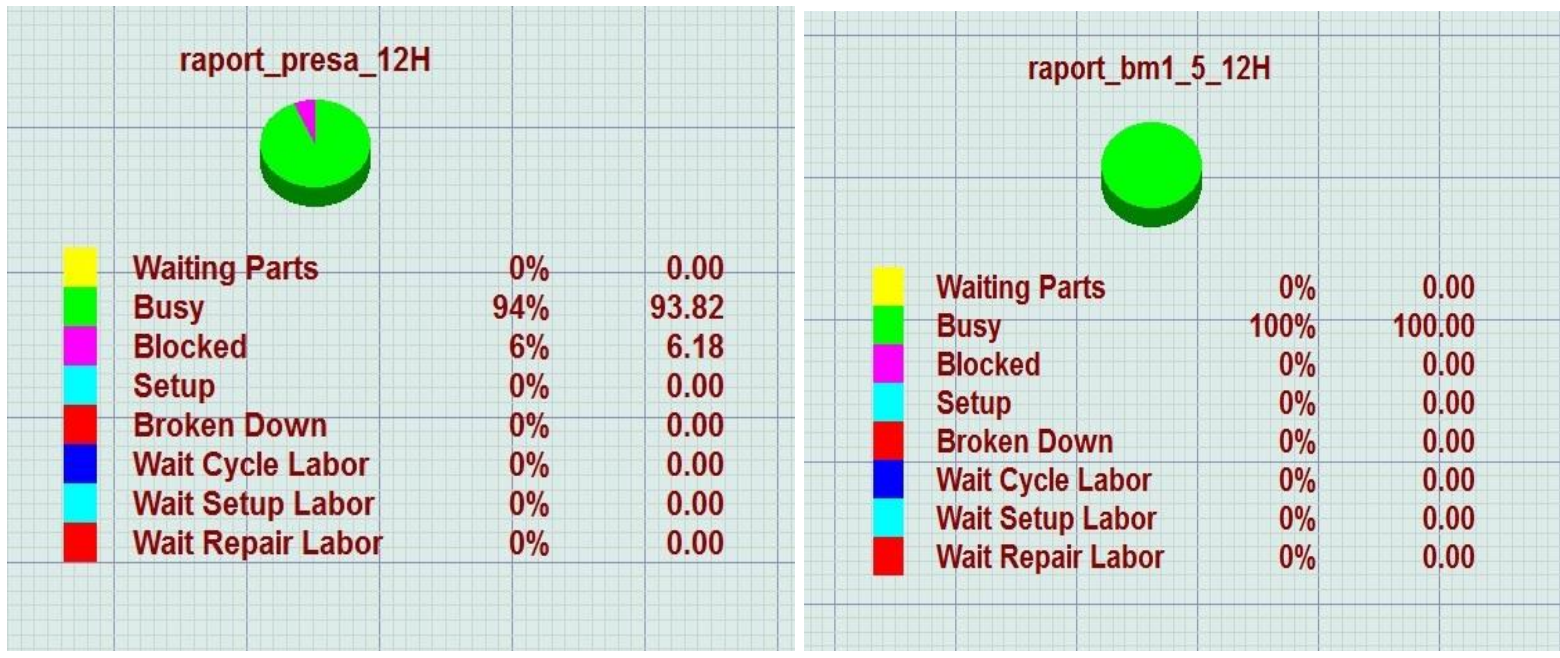

Fig. 3. (a) The cupper press report after the functional remodeling; (b) Bodymaker 1 report after the functional remodeling

The reports obtained after the functional remodeling show the following:

- $\quad$ a reduction of bottlenecks at the cupping press. (see figure 3 a). The bottlenecks thus dropped from $20 \%$ to 6 $\%$.

- the bodymakers function $100 \%$ of the time, and in this case the bottlenecks were eliminated (see figure $3 \mathrm{~b}$ ).

- at the necker the waiting time was eliminated, and now the necker works at $100 \%$.

- the $15 \%$ waiting time at the washer was eliminated and it now works at $100 \%$ (see figure $4 \mathrm{~b}$ ).

After the optimization, this line could produce 398 pallets of 5000 cans each, in 12 hours. This means 1.990 .000 cans and a $11 \%$ increase in efficiency. The new simulation of the system validates the solution resulted from the functional remodelling.

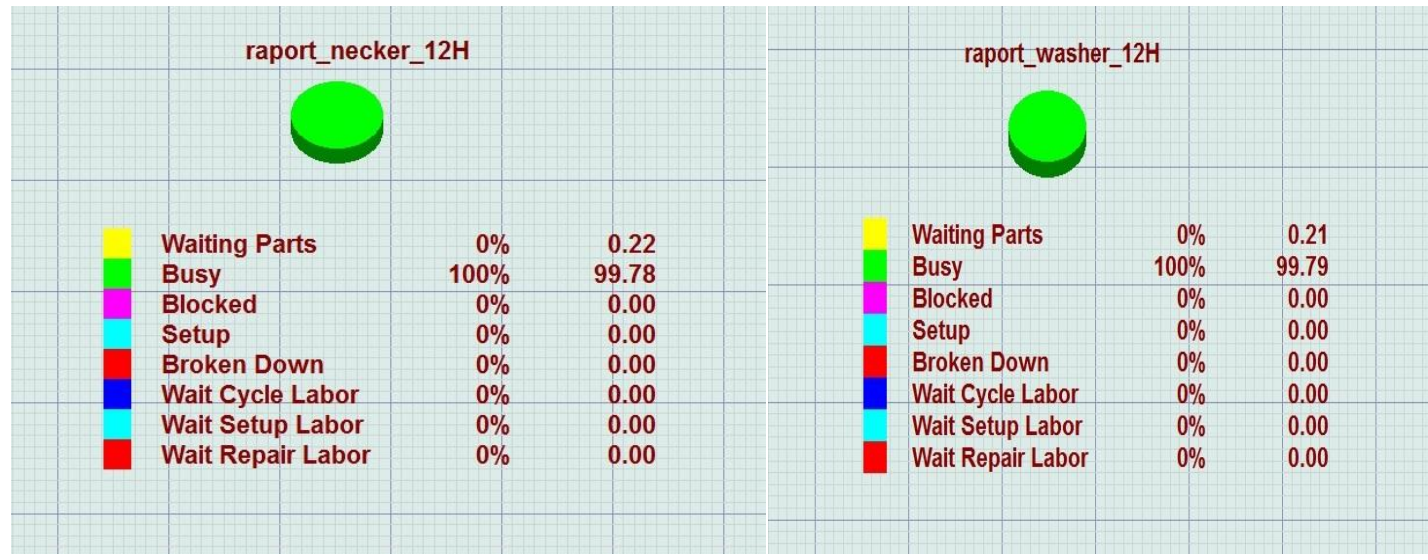

Fig. 4. (a) The necker report after the functional remodeling; (b) Washer report after the functional remodeling

\section{Conclusion}

When designing the layout of a manufacturing system, virtual models of different structural elements can be used, while in simulating the material flow in the manufacturing architecture, data from processes simulations can constitute input parameters. In this context of using data from different types of applications for defining and optimizing manufacturing architecture, data compatibility and data portability issues should not be neglected when choosing the software tools for supporting the optimal definition of a manufacturing architecture. 
In dealing with material flow management applied to manufacturing systems, one should consider using a specific algorithm for optimizing the associated architecture by modeling and then simulating the material flow trajectory within the system. This algorithm, illustrated in this paper by a case study, offers a structured modality to increase the productivity and profit in manufacturing architectures in order to respond to different requirements. Current needs and practice in industrial engineering determined us to adapt the general material flow theory and to develop specific algorithms like this one for diagnosis and optimization for manufacturing architectures using material flow management.

As can be noticed, our approach, although restrictive to industrial projects, can be however used to accommodate the advances in digital fabrication and the development of new manufacturing processes/technologies, thus responding to the current trend of mass-customization as a paradigm shift from mass production. Based on previous results we established the main future research direction as follows: improving performances analysis by developing new measuring tools; integrating the investment analysis in the material flow simulators; integrating engineering knowledge in material flow management; integrating material flow management with ERP (Enterprise Resource Planning) applications. We want to develop an algorithm that assures a quick system reconfiguration based on the client's needs without changing the system architecture and as well a database that can store the parameters that must be set for each structural element of the system using the parameterization specific to the product type.

\section{References}

[1] S. Xu, (2008) The concept and theory of material flow. Information Systems Frontiers, 10(5), 601-609, ISSN: 1387-3326 print, 1572-9419 online, doi: 10.1007/s10796-008-9113-4,.

[2] M. P. Groover (2012). Fundamentals of Modern Manufacturing: Materials, Processes, and Systems, John Wiley \& Sons, ISBN 978-1118393673.

[3] C.E.Cotet, D.Popescu, , (2014) - Material Flow Management in Industrial Engineering, in Encyclopedia of Information Science and Technology, Category: Industrial Engineering, Third Edition, Editor Mehdi KhosrowPour, Published in the United States of America by Information Science Reference (an imprint of IGI Global), pp. 3786 - 3794, ISBN 978-1-4666-5888-2 (hardcover) -- ISBN 978-1-4666-5889-9 (ebook) -- ISBN 978-1-46665891-2 (print \& access).

[4] J. Bekker, (2013). Multi-Objective Buffer Space Allocation with the Cross-Entropy Method. International Journal of Simulation Modelling, Vol. 12, No. 1, 50-61, doi: 10.2507/IJSIMM12(1)5.228.

[5] D.Popescu, D.Anania, C.E.Cotet, \& C. Amza, Fully automated liquid penetrant inspection line simulation model for increasing productivity, in: International Journal Simulation Modelling, 12(2), 82-93, ISSN online: 1740-2131, ISSN print: 1740-2123, 2013.

[6] O. Kerbrat, P. Mognol, \& J.Y. Hascoët, (2010). Manufacturability analysis to combine additive and subtractive processes, Rapid Prototyping Journal, 16(1), 63-72, ISSN 1355-2546.

[7] J.K.S.Nagel, , \& F.W. Liou, (2012). Chapter 11. Hybrid Manufacturing System Design and Development. In Manufacturing System, F.A. Aziz (Ed.), (p.223-246), Publisher InTech, ISBN 978-953-51-0530-5.

[8] M. Debevec, M. Simic, \& N. Herakovic, (2014). Virtual Factory as an Advanced Approach for Production Process Optimization, International Journal of Simulation Modelling, Vol. 13, No. 1, 66-79, doi: 10.2507/IJSIMM13(1)6.260.

[9] C.E. Cotet, C.L. Popa and F.Anghel, Manufacturing architecture design using discrete material flow management, in: International Journal of Simulation Modelling IJSIMM, volume 8, no. 4, , pp.206-214, ISSN 1726-4529, 2009.

[10] http://www.rexam.com 